\title{
Asian Philanthropy in 2020: An Analysis of the Li Ka Shing Foundation as a Positive Force for Good
}

\author{
Matthias Cheong \\ School of Business, University of Western Australia \\ Associate Director, IHS Markit \\ Email: matthias.cheong [AT] gmail.com
}

\begin{abstract}
COVID-19 has devastated lives and societies. In such a climate, it is even more important for humanity to focus on philanthropic efforts to uplift the most vulnerable in society. While much has been written about philanthropic organisations in the West, there is little written on Asia given its nascent status in giving and philanthropy. However, one strong example that can serve as a positive force in the region is the Li Ka Shing foundation, which focuses on education, healthcare, and the reduction of poverty. This paper highlights the Li Ka Shing foundation's growth in Asia, analyses its strategies, and offers it as an example for others to emulate in the hopes that more will step forward in what is a difficult time for humankind.
\end{abstract}

Keywords--- philanthropy; strategic analysis; financial analysis; poverty reduction; COVID-19

\section{INTRODUCTION}

Philanthropy, which means love of humankind, originated from a play 'Prometheus Bound' written by Greek playwright Aeschylus in 450 BC. Since then, philanthropy has been associated with charitable giving to create positive changes in the world. In a study by Johnson (2018), there is an increase in the number of philanthropists establishing foundations to focus, practice and amplify their social investments. The idea that institutional philanthropy can encourage more strategic investment approaches, facilitate collaboration, serve as a role model for others and have a greater impact on economic and social challenges is gaining momentum among philanthropists. In the same study, it was observed that only 2000 out of 260,358 foundations globally (representing $0.77 \%$ of the total) were located in Hong Kong. This appears to be a relatively small number compared to other developed countries such as the United States of America (USA; 86,203), Germany $(20,700)$, Switzerland $(17,110)$ and Australia $(5,000)$ - see Exhibit 1. 


\section{Foundations around the world}

Institutional philanthropy has a global reach. 260,358 foundations in 38 countries and Hong Kong were identified, representing only a partial picture of the sector.

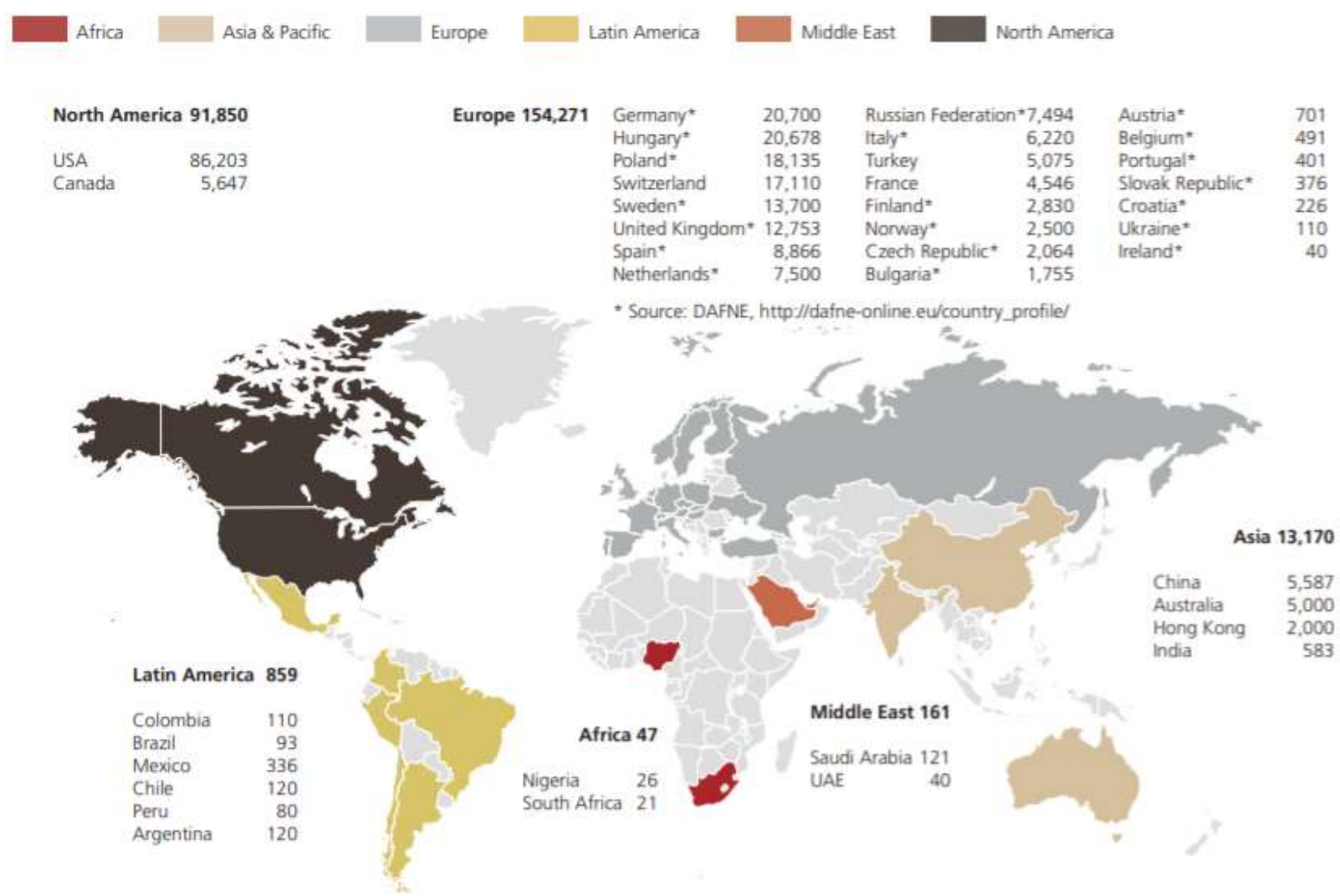

Exhibit 1: Number of foundations globally (Johnson 2018)

In terms of the total size of foundation assets per country, Hong Kong (USD 10.6 billion) was ahead of Australia (USD 8.7 billion) but significantly behind USD (USD 890 billion) and Germany (92.9 billion) - see Exhibit 2. 


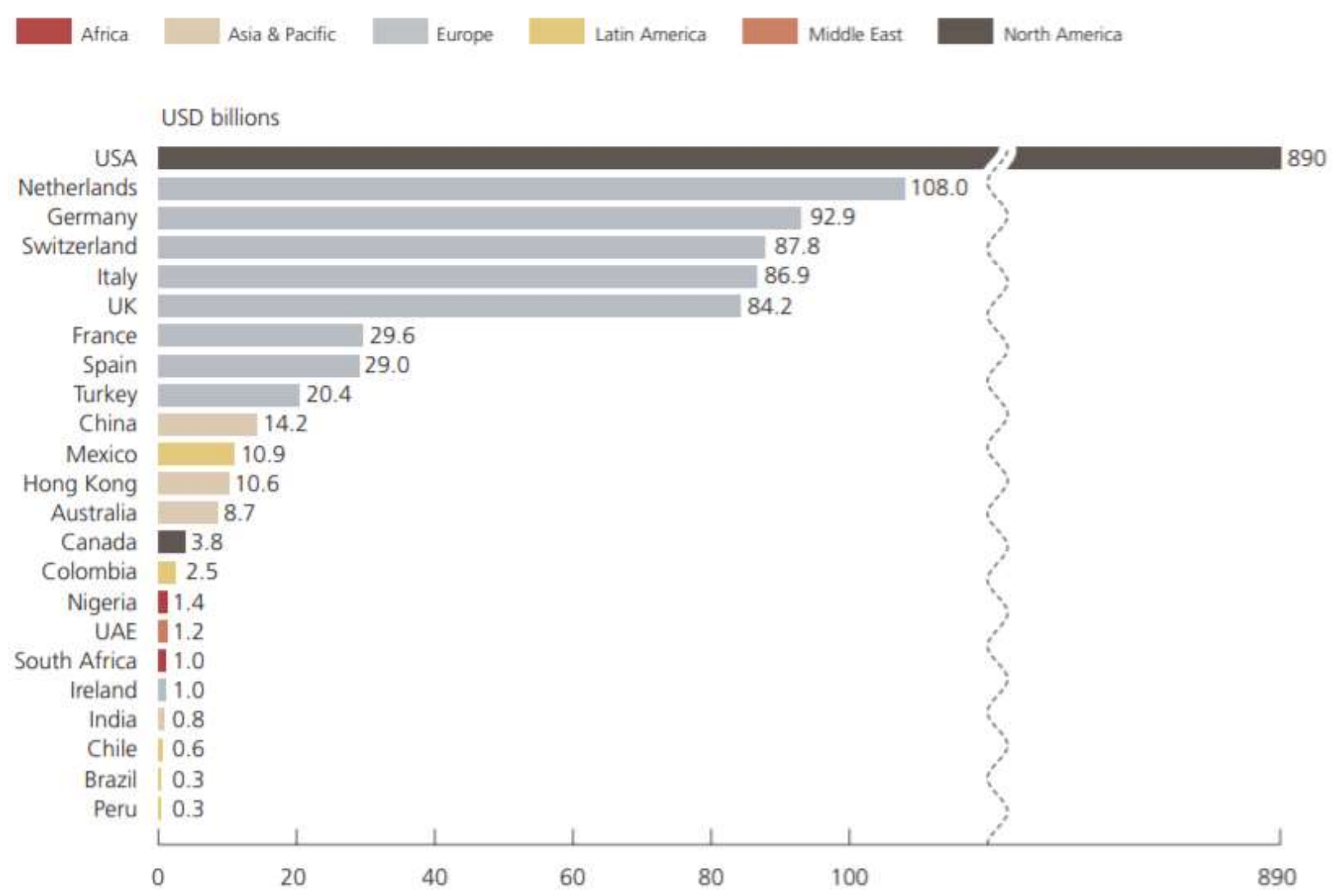

\section{Exhibit 2: Foundation Assets}

This paper focuses on one of the largest private independent foundation in Hong Kong - the Li Ka-Shing Foundation Limited (LKSF). The LKSF has assets of over HKD 27 billion (USD 3.48 billion) across 27 countries and regions, of which $80 \%$ of the initiatives are made within the Greater China region (which includes mainland China, Hong Kong, Macau and Taiwan).

\section{BIOGRAPHICAL AND CONTEXTUAL RESEARCH}

Li Ka-shing was born on 13 June 1928 in Chaozhou, Guangdong province, China. In 1940, Li fled with his family to Hong Kong to escape from the Japanese invasion of China. While in Hong Kong, Li and his father contracted tuberculosis (TB). While Li recovered from TB, his father unfortunately died from the disease in 1943. After his father's death, Li had to quit school at the age of 15 to support his family. Despite having limited education and skillsets, he found a job as a salesman in a plastics factory (Chan, 1996). As will be seen, this difficult time during his early years, his lack of access to education and health issues will be a driving force to fund education, healthcare, and reduce poverty as part of his foundation's goals .

Li's diligence at the factory soon saw his promotion to factory manager. Having learnt the skills of how to operate a plastic factory, Li proceeded to form his own plastics company, Cheung Kong Holdings Limited (Cheung Kong), manufacturing all kinds of plastics, and still operates today as one of the world's largest and successful multinational conglomerates. In Cheung Kong's first year, Li personally did the firm's accounts by learning accounting from second hand accounting textbooks as the firm could not afford to hire an accountant. However, Li's perseverance, strong leadership, business acumen and good relationships with both clients and suppliers, soon saw Cheung Kong's business flourish in the 1950s. By 1958, Cheung Kong's revenue hit HKD 10 million with a net profit of more than HKD 1 million. Li had finally broken free from the poverty cycle.

In 1966, Mao Zedong's Cultural Revolution, spread to Hong Kong, causing real estate prices to plummet as a result of the political riots (Phillips, 2016). Li's strong business acumen was in play again as bought huge chunks of land at these depressed prices and build properties on these lands, marking his first business expansion into real estate. Hong Kong's property prices recovered when the Cultural Revolution ended in 1976 and Cheung Kong made huge amounts of profits 
through the management and leasing of properties. With his substantial wealth, Li had always been contribution to charitably causes, though largely on an ad-hoc basis outside of an established charity or foundation, until 6 August 1980 when he set up the LKSF.

\section{PHILANTHROPIC MOTIVATIONS}

As a practising Buddhist, it is probable that Li was also motivated to give back to society based on the teachings of Buddhism. Buddhism views charity as a self-less act which reduces attachment to personal possessions so as to promote spiritual progress.

Li's motivation to give can also be partly attributed to his lack of access to education in his youth and his difficult childhood which saw him having to enter the workforce at an early age to make ends meet. The revisitation of such memories would most probably cause him to feel distressed which would compel him to help these people in order to reduce such distress - see Path 2 'Distress Reduction (egoistic) in Exhibit 3.

Furthermore, Li's motivation to give can also be partly attributed to altruistic reasons - see Path 3 'Altruistic' in Exhibit 3. Li could have adopted the perspective of a helpless and poor person and empathised with them. Again, his difficult experience during his younger years would have helped him emphasize with those in need. This would motivate him to help the person out of genuine concern for their well-being.

Lastly, it is possible that $\mathrm{Li}$ was also motivated to give in order to gain non-financial rewards such as to gain reputation and standing in society - see Path 1 'Reward-seeking' in Exhibit 3. However, this type of motivation is unlikely for Li as it is directly in conflict with his Buddhist values which state that one should not expect returns when making a charitable gift. Furthermore, the accepted norm to gain standing in society from a traditional Asian value context was to accumulate wealth to pass these down to his/her family descendants, building a legacy or dynasty of sorts (Wong, 2020). Simply put, if Li wanted reputation and standing in society, his immense wealth would have already secured that goal many times over. His charitable acts of giving can thus be largely attributed to the other reasons set out above.

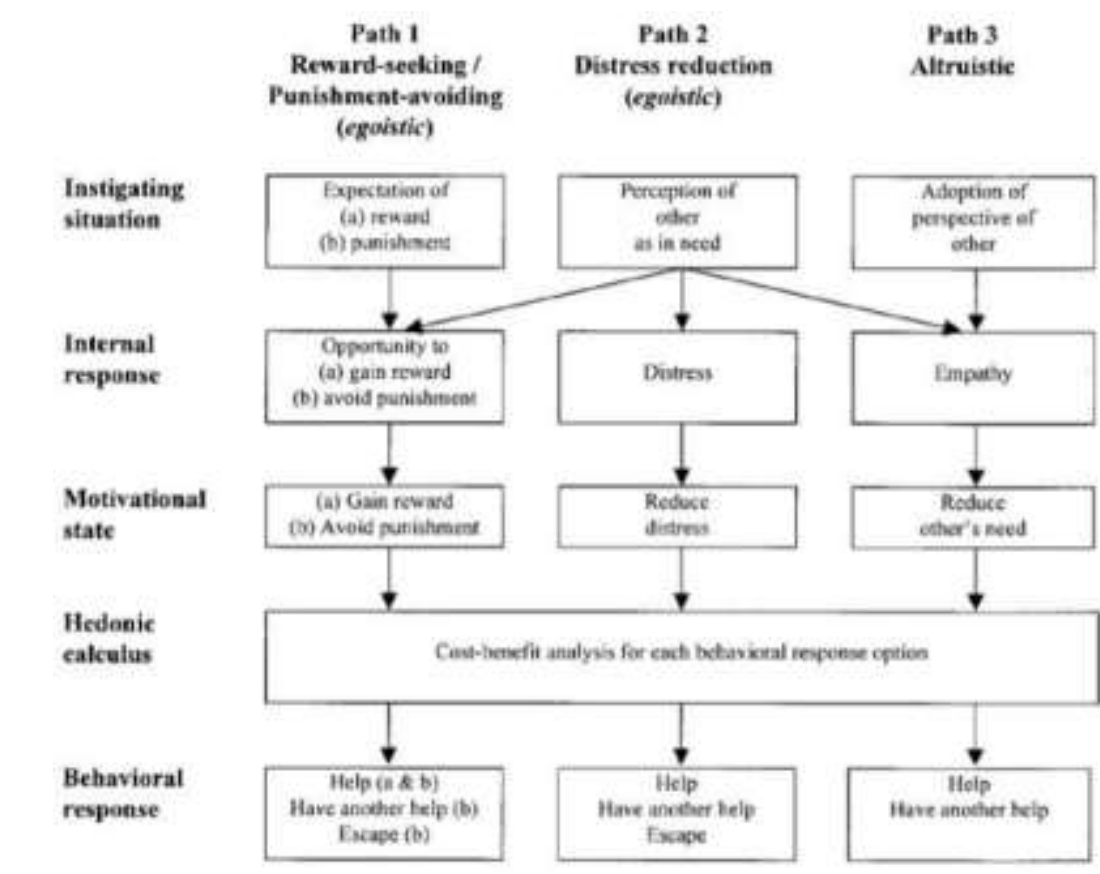

Exhibit 3: Egoistic and altruistic paths to helping adapted from Batson's (1987) flowchart

\section{PHILANTHROPIC ACTIONS}

Before 1980, Li had already donated charitable causes. However, in 1980, he decided to form a foundation and allocate assets to it, so that the foundation would be able to benefit more many generations of people through scaling of activities and resources. Via the LKSF, Li was now able to maximise his contribution to society. 
The initial goals of the LKSF was to focus on education and healthcare initiatives. These were influenced by Li's childhood experiences of living in poverty and with TB. Therefore, Li wanted to provide educational opportunities to the poor so that they can be equipped with skills and knowledge to find employment, thereby breaking out of the poverty cycle. Li also understood what it felt to be sick and helpless through his episode with TB. Hence, he wanted to fund healthcare initiatives that can alleviate the physical pain that patients suffer so that they can lead fuller and more meaningful lives.

In the 1980s, the LKSF built the Shantou University and Chaozhou Hospital in Guangdong province. These are examples of a traditional philanthropy approach which seek to address the root causes in education and healthcare respectively by building lasting institutions that can effect changes in society. Choosing Shantou as LKSF's first location to invest in education may be partly due to Shantou's status back then as one of four Special Economic Zones (SEZ) in mainland China. A SEZ is an area which enjoys favourable business and trade laws to attract foreign direct investment. Hence, Li might have believed that a positive feedback loop could be achieved in Shantou by having a university situated there to train graduates who are then able to contribute to the government's efforts to grow its economy which in turn would allow the university to attract more students. Shantou is also located in Li's hometown in the Guangdong, which could have also affected Li's decision in establishing the charitable institutions there.

Separately, the LKSF had also partnered with the China Disabled Persons' Federation (CDPF) to launch the Cheung Kong New Milestone Program (CKNMP) with the aim of helping disabled people. The CDPF partnership, initially focused on providing prosthetics installations. However, the CKNMP was so successful that it in 2000, it was expanded to offer education, rehabilitation, employment and group support services to disabled people. The partnership with CDPF is an example of catalytic philanthropy where root causes are addressed through catalytic investments in systems change and partnerships that are confident in market and technical solutions.

In terms of contributions to social initiatives, the LKSF had contributed to various disaster relief efforts over the years. However, it was only in 2009 that the LKSF started to embark on initiatives that encourage people to adopt a culture on giving via programs such as 'Love Ideas, Love HK'. This program encouraged Hong Kong residents to submit innovative and creative ideas or vote for projects that encourage compassion or charitable giving (LILHK 2020).

\section{LEGAL STRUCTURE}

A charitable organisation in Hong Kong can be one of the following five forms (Law Commission of Hong Kong, 2013):

- An unincorporated association, which is usually registered under the Societies Ordinance (Cap 151 of the Laws of Hong Kong).

- A charitable trust.

- A company incorporated under the Companies Ordinance (Cap 622 of the Laws of Hong Kong).

- A statutory body formed under a specific ordinance.

- An incorporated management committee formed under the Education Ordinance (Cap 219 of the Laws of Hong Kong).

Li had established the LKSF as a company incorporated under the Companies Ordinance, specifically a company limited by guarantee (ICRIS 2020). This form allows the LKSF to have a distinct legal personality and it can hold assets and sue and be sued in its own name. Hong Kong law treats this entity as an independent legal entity distinct from the persons who form it, or participate in it as a member or director. Furthermore, this legal structure does not have share capital. Instead of having shareholders, there are directors who participate in the company like shareholders, but the articles of incorporation will generally prohibit the company from making any distribution of either the company's assets or income to the directors by way of a dividend, bonus, remuneration, or any other form. Finally, the sources of LKSF's income primarily comes from private sources such as the Li family and corporations like Cheung Kong which are used to support educational, healthcare, social and cultural initiatives.

\section{STRATEGY AND PROCESSES}

According to McKinsey (2013), there are four types of categories in which donor support can be classified - see Exhibit 4. This paper discusses the strategies and processes that LKSF deployed with reference to this McKinsey framework. 


\section{Across sectors, modes of intervention and corresponding donor support can be classified in four distinct categories}

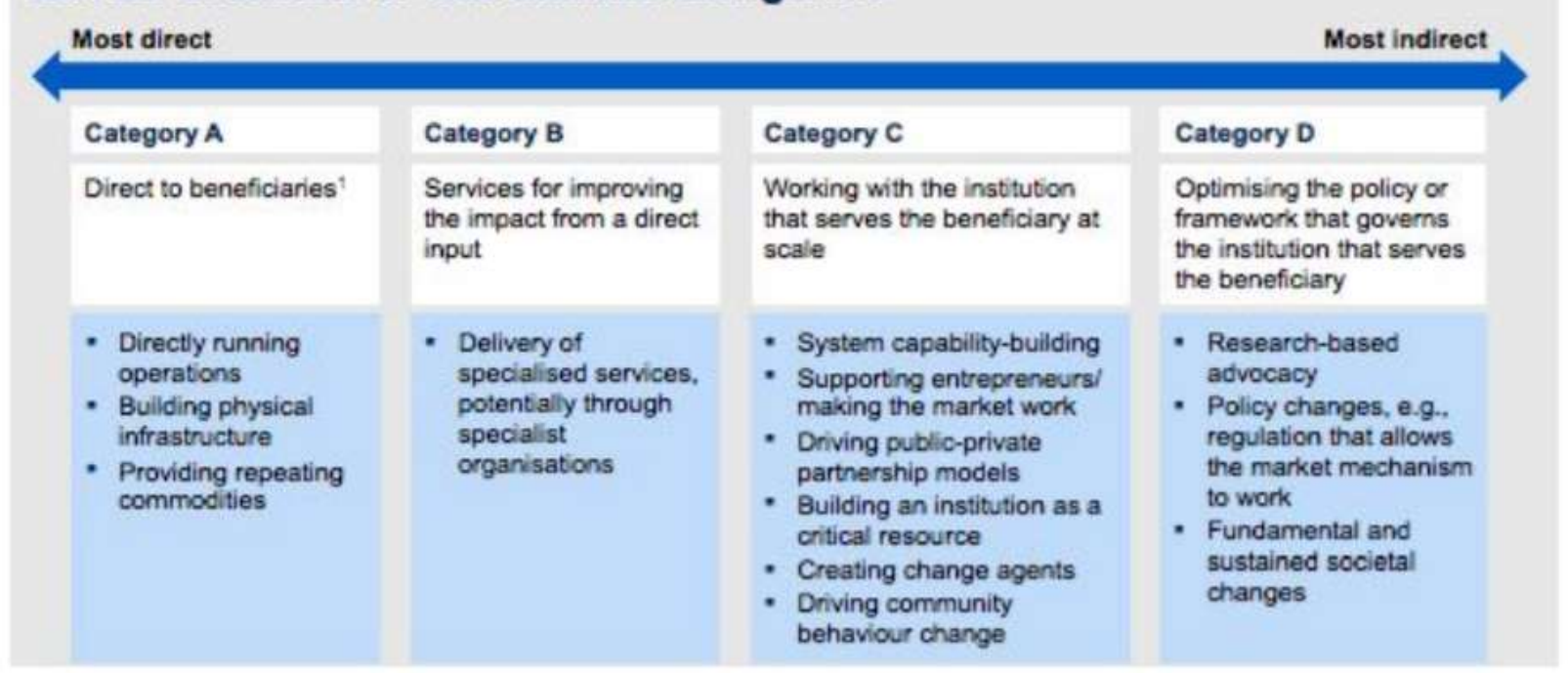

Exhibit 4: Categories of donor support (McKinsey 2013)

In the 1980s, the LKSF focused on healthcare and education initiatives as these were arguably easier to solve then social initiatives such as changing people's behaviour to give more to society. The strategy was to focus on provincial and national initiatives with the support of the provincial and national government in mainland China (Category $\mathrm{C}$ type). Hence the processes that LKSF carried out this strategy was to work with the local government in Guangdong province to build the Shantou University and Chaozhou Hospital, and partnering with the CDPF to provide healthcare services to the disabled people. One reason the LKSF focused on mainland China could be because of its geographical proximity to Hong Kong (where Li and the LKSF was based in) thereby making it easier for the LKSF to monitor the progress of its initiatives. Another reason could be that $\mathrm{Li}$ had strong relationships with the Chinese government officials thus increasing the probability of success of the LKSF's initiatives there. Other reasons could be that Li was more familiar with mainland China based on the same ethnicity and cultural background, which motivated him to focus the foundation's efforts there.

In the 1990s, the LKSF scaled its initiatives through system capability building and deeper partnerships with the national Chinese government (Category C type). Examples include rebuilding 70 primary schools in Chaozhou. In 1997, the LKSF partnered with China's Ministry of Education (MOE) to establish the Cheung Kong Scholars Program (CKSP). This program was one of two flagship programs (the other being the Thousand Talent Program) supported by the MOE to nurture Chinese talent in science and technology. The CKSP is an example of a Category D type of education initiative where the LKSF worked with the MOE to establish policies that have fundamental and sustained societal impact. Another notable strategy during this period is that the LKSF decided to expand its philanthropic outreach globally - through building a new research centre at Cambridge University and donations to Stanford University for hepatitis research.

In the 2000s, the LKSF started supported more Category C type healthcare initiatives in rural areas in Shaanxi and Hainan, making an expansion from the foundation's earlier approach in only targeting high density cities such as Shantou and Chaozhou. Starting from 2009, the LKSF embarked on social initiatives that encourage people to engage in charitable behaviour via programs such as the such as the 'Love Ideas, Love HK'. One possible reason that the LKSF started to target behaviour change now is because it had experienced much success in tackling the simpler problems in education and healthcare thus far and believe it is ready to tackle the more complex problems in changing people's attitudes towards charitable giving. Another possible reason is that Li could have sensed the growing discontentment among the Hong Kong citizens in late 2000s. Therefore, one way to help reduce such discontentment and promote social stability would be to embark on programs that encourage people to give back to society, practise compassion and be grateful for what they currently have. The 'Love Ideas, Love HK' is an example of a catalytic philanthropy approach that the LKSF adopted to encourage charitable giving behaviour. 


\section{IMPACT ASSESSMENT AND LEARNING}

The LKSF has made a significant impact on education and healthcare in the Greater China region. In absolute numbers, the LKSF has helped produce 150,000 graduates, served more than 17 million patients and provided training opportunities for 15 million rural residents - see Exhibit 5.
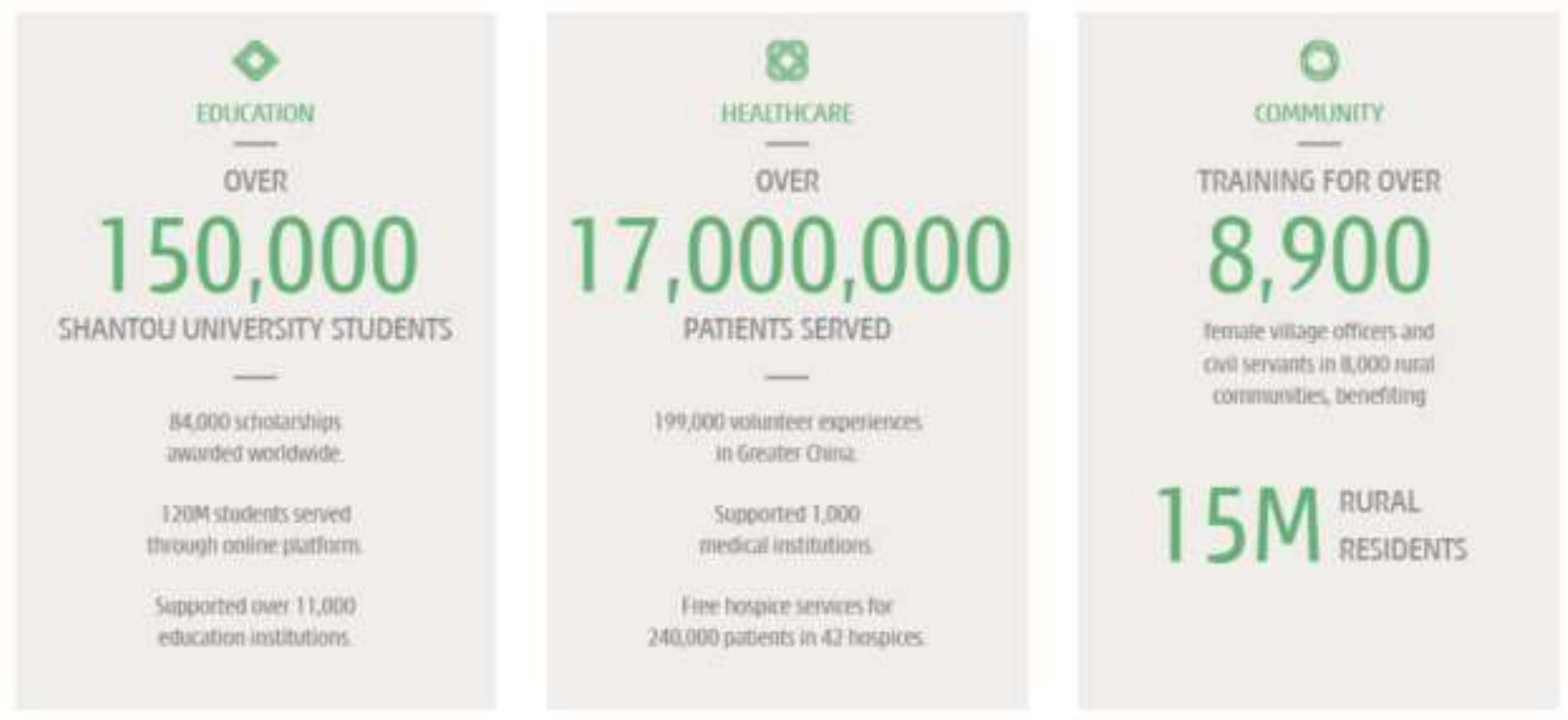

Exhibit 5: The LKSF's Impact on Education, Healthcare, \& the Community (LKSF 2020)

However, it is difficult to measure the impact of behaviour change in peoples' attitudes towards charitable giving. There are no statistics provided by the LKSF on how many people had started to donate to charitable causes as a direct result of the LKSF's social initiatives such as the 'Love Ideas, Love HK' campaign. Future research could be done to collaborate with the LKSF to determine the impact of the LKSF's social initiatives towards charitable giving behavioural changes among program participants.

The first key lesson is that philanthropists can amplify their impact through establishing foundations rather than relying on their personal strength. Through the LKSF, Li was able to pool together resources and focus efforts on scaling educational, healthcare and social initiatives. Had Li not set up a foundation and relied on his own personal strength instead, it would probably be difficult to repeat the results that the LKSF has achieved.

The second key lesson is that collaborating with the government on healthcare and education helps to drive scale and impact. That the LKSF could help millions of students, patients and rural residents can be attributed to Li's strong relationships with the provincial and national government, the alignment of the LKSF's initiatives with the government's long-term strategy and both parties' commitment to the shared goals.

The third key lesson is that the formation and execution of the philanthropic strategy is important for having a successful impact. The LKSF started on a relatively small scale first, by building one university and hospital in Guangdong province. Only when it achieved success with its initial investments, did it broaden its scope to include investing in institutions and programs based internationally. Overall, this paper notes that the foundation's transition from a regional to international approach was well executed. Also, the strategy to focus on simpler problems such as education and healthcare in the foundation's early years proved to be on point as the impact could be easily measured in terms of number of students and patients served respectively. Once the foundation had garnered sufficient success in tackling these low hanging fruit, did it then decide to branch into more complex issues such as encouraging people to give more towards charitable causes.

\section{CONCLUSION}

As can be seen, Li's early childhood experiences has a strong influence on the direction and focus of the LKSF he helped set up. His health difficulties and lack of education in his younger years, helped the LKSF to focus on healthcare and education initiatives. The LKSF also has a broader poverty reduction goal which is consistent with his own experiences with poverty in his early years. 
To maximise the impact of his foundation, Li had strategically set it up as a Company limited by guarantee. This structure would contain no shareholders but have directors that form the governing board instead. In choosing to set up LKSF as an independent foundation, Li wanted to leverage on foundation's structure to amplify his healthcare, education and social investments.

The LKSF's initial strategy was to invest in education and healthcare by building long-lasting institutions in one province in mainland China. Based on its initial successes, it then expanded its investments to regionally within Greater China before going international. Complex problems such as encouraging people's behaviour to give was only tacked in later years once it had achieved success in its education and healthcare initiatives.

Finally, the three key takeaways from the LKSF is that philanthropists can amplify their impact through establishing foundations rather than relying on their personal strength; collaborating with the government on healthcare and education helps to drive scale and impact; and that the formation and execution of the philanthropic strategy is important for having a successful impact.

\section{REFERENCES}

- Batson, C. D. (1987). "Prosocial motivation: It is ever truly altruistic?” In L. Berkowitz (Ed.), Advances in experimental social psychology. 20, 65-122. New York: Academic Press

- Chan, A. B. (1996). Li Ka-Shing: Hong Kong's Elusive Billionaire. Oxford University Press.

- Huang, H. \& Woo, P.C. (2020). Charitable organisations in Hong Kong: overview https://uk.practicallaw.thomsonreuters.com/w$\underline{0194010}$ ?transitionType $=$ Default $\&$ contextData $=($ sc. Default $) \&$ firstPage $=$ true

- Integrated Companies Registry Information System https://www.icris.cr.gov.hk/csci/cns basic_comp.do

- Johnson, P.D. (2018). Global Philanthropy Report: Perspectives on the global foundation sector. https://cpl.hks.harvard.edu/files/cpl/files/global_philanthropy_report_final_april_2018.pdf?m=1524750312

- $\mathrm{Li} \quad \mathrm{Ka} \quad$ Shing $\quad$ Foundation. (2020). Inspiring Change Since 1980. https://www.lksf.org/timeline/

- Love Ideas, Love Hong Kong (LILHK). (2020). About Love Ideas, Love Hong Kong https://www.loveideas.hk/about loveideas.aspx?lang=en-US

- McKinsey \& Co. (2013). Designing Philanthropy for Impact: Giving to the biggest gaps in India https://www.mckinsey.com/ /media/mckinsey/dotcom/client_service/social\%20sector/pdfs/designing_philanthr opy for impact.ashx

- Phillips, T. (2016). The Cultural Revolution: all you need to know about China's political convulsion https://www.theguardian.com/world/2016/may/11/the-cultural-revolution-50-years-on-all-you-need-to-knowabout-chinas-political-convulsion

- Shantou University. (2018). STU Introduction. http://english.stu.edu.cn/index.php?option=com content\&view=article\&id=17\&Itemid=24\&lang=en

- Wong, P. (2020). Li Ka Shing. Kanyin Publications 